\title{
Introduction of Directive 2002/44/EC
}

\author{
Hee Sok Park
}

Department of Industrial Engineering, Hongik University, Seoul, 121-791

\begin{abstract}
Objective: The aim of this paper is to introduce the Directive 2002/44/EC on the minimum health and safety requirements regarding the exposure of workers to the risks arising from vibration. Background: Human beings interact with machinery, and contact with vibration is commonplace. Unfortunately, continuous exposure to mechanical vibration can lead to physical injury. And standards are needed for identifying those at risk and for taking steps to mitigate the problem and reduce risk of injury. Method: The contents of the Directive were summarized and discussed, especially against its ISO counterparts. Results: The Directive deals with minimum safety and health prescriptions relative to workers' exposure to risks due to mechanical vibration. This directive specifies exposure limit values and action values. It also specifies employers' obligations with regard to determining and assessing risks, sets out the measures to be taken to reduce or avoid workers' exposure. Finally, it details how to make exposed workers aware of this issue. Conclusion: In spite of some limitations, it has recently been transcribed into all national laws of member States of European union. Application: The results of the paper might help to establish or update the domestic standards on vibration.
\end{abstract}

Keywords: Human vibration, Standard, Directive 2002/44/EC

\section{Introduction}

진동은 물체가 일정한 주기 (period)를 가지고 떨리는 현 상으로서, 인체에 전달되는 범위에 따라서 전신진동 (whole body vibration: WBV) 과 국소진동(local vibration)으로 대별할 수 있다. 전신진동이란 주로 운송수단과 건물을 이 용할 때 발생하는 형태로서, 지면, 좌석의 좌판(seat pan), 등받이 등 몸을 지지하고 있는 면을 통하여 몸 전체에 진동 이 전해지는 경우를 일컫는다. 국소진동은 주로 동력 수공구 (powered hand tools)를 잡고 일할 때 손, 팔, 어깨에 진동 이 전해지는 것처럼 몸의 일부에 진동이 전달되는 경우로, 手腕진동 (hand-arm vibration: HAV)이라고도 한다.

진동이 인체에 미치는 영향을 분석하고 예방하기 위해서 는 진동의 측정과 평가방법에 관한 표준이 필요하다. 이에 관한 대표적인 표준으로는 국제표준화기구(International Organization for Standardization: ISO)와 유럽연합
(European Union: EU)이 각각 제정한 표준을 들 수 있다. $\mathrm{ISO}$ 에서 제정한 인체진동에 관한 표준(예: $\mathrm{WBV}$ 는 ISO 2631, HAV는 ISO 5349)은 제정된 지가 오래되어 여러 국 가의 연구자들이 이에 관하여 많은 연구를 해왔다. 그리고 우리나라에서는 ISO 2631 과 5349표준을 기술적인 내용의 변경 없이 한글로 번역하여 $\mathrm{KS}$ 표준으로 제정하고 있다.

반면, $\mathrm{EU}$ 표준에 대해서는 국내에서 관심과 이해가 상대적 으로 낮은 실정이다. 이에 본 기술논문에서는 인체진동에 관 한 $\mathrm{EU}$ 표준을 소개 및 토의하고자 한다. 본 논문이 추후 우 리나라 연구자들의 인체진동 관련 연구수행과, 우리나라의 관련 표준을 제/개정하는데 도움이 되기를 기대한다.

\section{Directive 2002/44/EC}

본 표준의 명칭은 'Directive 2002/44/EC on the minimum 
health and safety requirements regarding the exposure of workers to the risks arising from physical agents (vibration)'으로서, 2002년 6월에 The European Parliament and the Council of the European Union에 의하여 제 정되었다. 본 표준은 유럽연합을 구성하는 27 개 국가들은 의무적으로(mandatory) 지켜야 하는 규정이며, 그들 국가 간 차이는 있지만 법적인 효력을 갖는다.

본 표준의 특징은 $\mathrm{WBV}$ 과 $\mathrm{HAV}$ 에 대하여 노출 및 조처한 계 값을 제시하고 있는 점이다. 그리고 과도한 진동의 발생 시 취하여야 하는 기술적, 관리적 조처를 명기하여 안전 · 보 건 상 위험이 발생하지 않도록 할 것을 명시하고 있다. 총 16 개 조항(article)이 4개 section으로 구성되어 있으며, 부 록에서는 진동수준을 평가하는 기술적인 방법을 규정하고 있다.

\subsection{Section 1: General provisions}

Section 1에서는 본 표준의 목적과 범위가 기계진동의 건 강 - 안전상 위험으로부터 작업자를 보호하는 최소한의 요구 사항(minimum requirements)이라고 규정하고 있다. 그리 고 $\mathrm{HAV}$ 와 $\mathrm{WBV}$ 의 정의와 각각의 주된 영향을 제한 $\mathrm{HAV}$ 는 혈관계, 근골격계와 신경계; $\mathrm{WBV}$ 는 척추)하고 있다. 또한 8시간 작업시간 기준으로 노출한계(exposure limit value) 와 조처한계(action limit)를 제시하고 있으며, 이 때 사용되 는 물리량은 가속도(단위: $\mathrm{m} / \mathrm{s} 2$ )이다.

Table 1. Exposure limit values and action values(unit: $\mathrm{m} / \mathrm{s} 2$ )

\begin{tabular}{c|c|c}
\hline & HAV & WBV \\
\hline Daily exposure limit value & 5 & 1.15 \\
\hline Daily exposure action value & 2.5 & 0.5 \\
\hline
\end{tabular}

\subsection{Section 2: Obligation of employers}

Section 2에서는 작업자가 과도한 수준의 진동에 노출되 는 경우, 고용주의 포괄적인 의무를 명시하고 있다. 그 의무 의 시작점은 작업자가 노출되는 진동수준을 측정하고 평가 하는 것이다. 단, 진동의 측정에는 지식과 경험이 요구되므 로 그러한 요건을 갖춘 사람이 수행하여야 한다. 측정과 평 가는 적절한 주기에 걸쳐 이루어져야 하며, 그 데이터는 보 관되어야 한다. 그리고 현재의 작업방법과 도구를 관찰할 것을 규정하고 있다. 그 외 세부적인 의무로서는, 전술한 Table 1 의 한계치에 주의해야 하는 의무, 진동이 작업자의 안전 · 보건에 미치는 직 · 간접적인 영향에 대하여 주의해야 하는 의무, 진동과 작업장/타 작업도구와의 상호작용에 대하
여 주의해야 하는 의무, 작업도구의 제조사가 제공하는 정보 에 대하여 주의해야 하는 의무, 진동수준을 경감시킬 수 있 는 대체장비를 인식해야 하는 의무, 정상적인 작업시간을 초 과하는 진동노출에 주의해야 하는 의무, 저온 환경을 포함한 작업환경에 대하여 주의해야 하는 의무, 그리고 안전 · 보건 과 관련된 정보에 대하여 주의해야 하는 의무 등을 규정하고 있다.

특히 작업자에게 전달되는 진동수준이 조처한계를 상회하 는 경우에는 진동원 (源) 을 제거하거나 인체에 전달되는 진 동수준을 최소화시키는 다양한 기술적 조처(예: 작업방법, 작업도구, 작업장의 변경 또는 유지 - 보수)와 관리적 조처 (예: 작업자 교육, 노출의 지속시간과 강도의 제한, 적절한 휴식시간을 포함한 작업일정 조정, 보호구의 지급 등)를 실 행해야 함을 포함하고 있다.

그리고 작업자에게 전달되는 진동수준이 노출한계를 상회 해서는 안됨을 명기하고 있다. 만약 노출한계를 상회하는 경 우에는 노출한계 이하로 진동수준을 경감하는 조처를 즉시 실행하여야 한다. 또한 노출한계를 상회하게 되는 원인을 파 악하고, 이러한 현상이 재발되지 않도록 필요한 조처들을 강 구하여야 한다. 진동으로 인한 위험에 처해 있는 작업자의 요구가 있을 시에는 본 조항에서 제시하고 있는 적절한 조처 를 취하여야 한다.

작업자와 작업자 대표에 대한 교육·훈련의 내용과 관련 해서는, 진동노출을 제거 - 경감시키는 여러 조처, 노출한계와 조처한계 값, 진동수준 측정과 평가의 결과, 상해(injury)로 인한 여러 증후(signs)의 식별과 보고방법, 건강 감시(health surveillance) 와 관련된 작업자의 권리, 안전한 작업방법 등 이 포함되어야 한다.

마지막으로, 본 표준에서 언급되는 제반 사항들에 대해서 작업자 및 작업자 대표와의 협의와 참여가 필요함을 기술하 고 있다.

\subsection{Section 3: Miscellaneous provisions}

여기서는 $\mathrm{EU}$ 회원국들이 본 표준의 4 조 1 항(진동수준의 측정 - 평가와 관련한 고용주의 의무)의 실행 결과에 따라, 작업자의 건강 감시를 위한 적절한 조처를 국내 법이나 표준 의 형태로 도입할 것을 요구하고 있다. 이 국내 규제에는 진 동으로 인한 질병이 있는 것으로 판명되면 작업자에게 그 결과와 함께 관련 정보를 즉시 통보해 주어야 하는 의무, 작 업자 개인별 건강 기록을 작성하고 유지함 등이 포함되어야 한다.

그리고 본 표준의 적용시점과 경과규정, 그리고 예외규정 (예: 선박이나 항공기 탑승 중의 전신진동) 등을 규정하고 있다. 마지막으로 $\mathrm{EU}$ 구성국가들의 $\mathrm{EU}$ 에 대한 보고의 의무 
(예: 5년 주기로 본 표준이 어떻게 실행되었는지를 노·사 양측의 의견을 포함하여 보고함) 등을 기술하고 있다.

\subsection{Annex: Assessment of exposure}

부록에서는 $\mathrm{HAV}$ 과 WBV각각에 대하여 진동 가속도를 측정하고 평가하는 방법으로 ISO 5349-1(2001) 과 ISO 2631-1 (1997)에서 제시하는 방법을 적용할 것을 규정하 고 있다.

\section{ISO Standards}

$\mathrm{EU}$ 표준보다 역사가 길고, 많이 적용되고 있는 ISO표준 (5349-1, 2631-1) 과 간략히 비교하고자 한다. 이 ISO표 준들은 한글로 번역되어 KS B ISO 5349-1(2004)와 KS B 0710-1(2001)로 제정되어 있다.

\subsection{ISO 5349-1(2001)}

본 표준은 $\mathrm{HAV}$ 의 측정과 평가에 관한 일반적인 사항에 대하여 규정하고 있다. 가속도계(accelerometer) 부착방법, 대상이 되는 주파수 범위 $(8 \sim 1,000 \mathrm{~Hz})$ 등의 기초적인 사항 에서부터 진동수준 분석을 위한 가속도 값의 변환 등에 대 한 사항들을 다루고 있다.

진동이 인체에 미치는 영향은 진동파의 주파수에 따라 다 르므로(Figure 1) 본 표준에서는 주파수 별로 다른 주파수 가중(frequency-weighted) 가속도 값을 사용하고 있다. 그리고 진동이 전달되는 시간 동안 측정된 가속도 값의 root mean square (RMS) 값을 사용한다.

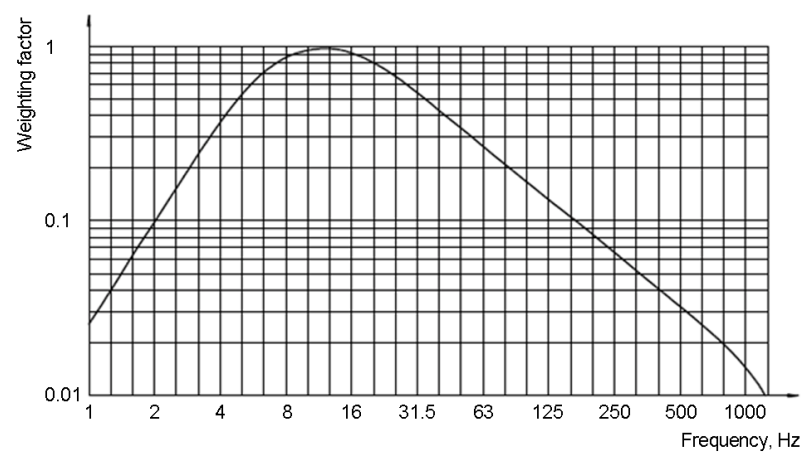

Figure 1. Frequency-weighting curve for HAV

ISO 5349-1의 1986 년 판에는 X, Y, Z축의 가속도 값
중 가장 큰 가속도 값을 나타내는 축(dominant axis)의 가 속도 값을 4시간 기준 주파수 가중 에너지등가 가속도로 변 환하여 진동수준을 평가하였으나, 2001년 개정판에는 3축 방향의 가속도를 벡터 합으로 합산한 8시간 기준 주파수 가 중 에너지등가 가속도를 사용한다.

또한 진동성 백지증(vibration white finger)의 초기증상 인 손가락 창백함(finger blanching)의 유병율(prevalence) $10 \%$ 기준으로, 8 시간 기준 가속도 값과 노출 년수 간의 양 -반응 관계(dose-response relationship) 가 Figure 2와 같이 부록에 제시되어 있다.

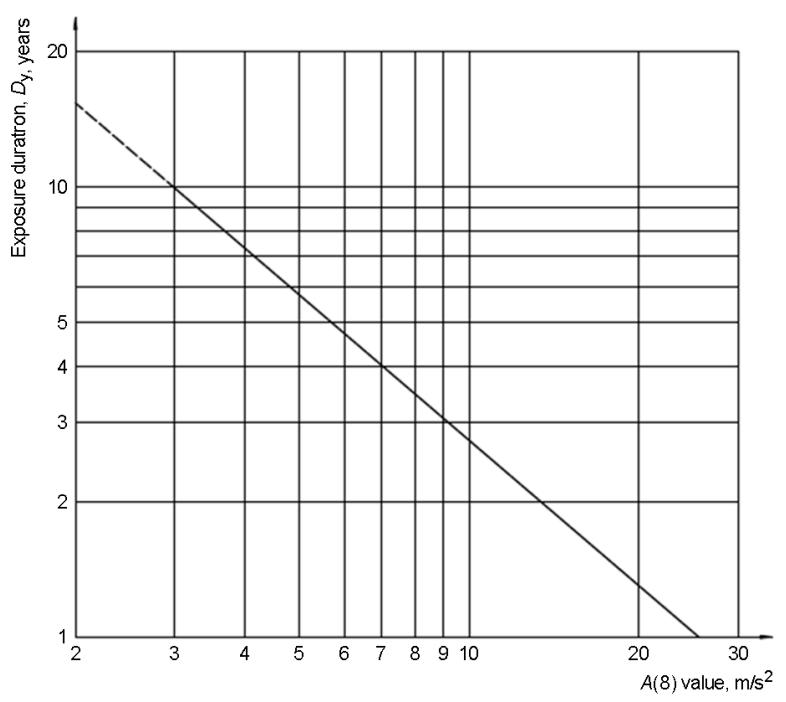

Figure 2. Vibration exposure for predicted $10 \%$ prevalence of vibration-induced white finger in a group of exposed persons

\subsection{ISO 2631-1(1997)}

본 표준은 1997년도에 개정되었고, 최근 2010년도에 추 가 수정판(Amendment 1)이 나왔다. 본 표준에서는 $\mathrm{WBV}$ 의 영향으로서 (척추)건강, 안락함(comfort), 지각(perception) 능력, 멀미 등 4 개 영역으로 구분하여, 각각에 대하여 다른 주파수 가중치를 제시하고 있다. $\mathrm{WBV}$ 의 척추질환에의 영향 에 관해서는 이전 판과는 달리 노출한계를 제시하지는 않고 주의영역 (caution zone) 만을 제시하고 있다(Figure 3, 2개 실선 간의 영역). 그 이유는 척추질환의 발생과 악화에 영향 을 주는 데에는 진동 이외에 많은 요인들이 작용하기 때문이 라 사료된다.

안락함 역시 진동 이외의 여러 인자에 의해서도 영향을 받 으므로 한계치를 제시하고 있지 않다. 대신, 운송수단 등에 의한 안락감에 대한 참고치가 Table 2 와 같이 나타나 있다 (가속도 값: 3 축에서 측정된 가속도 값의 벡터합산 RMS값). 


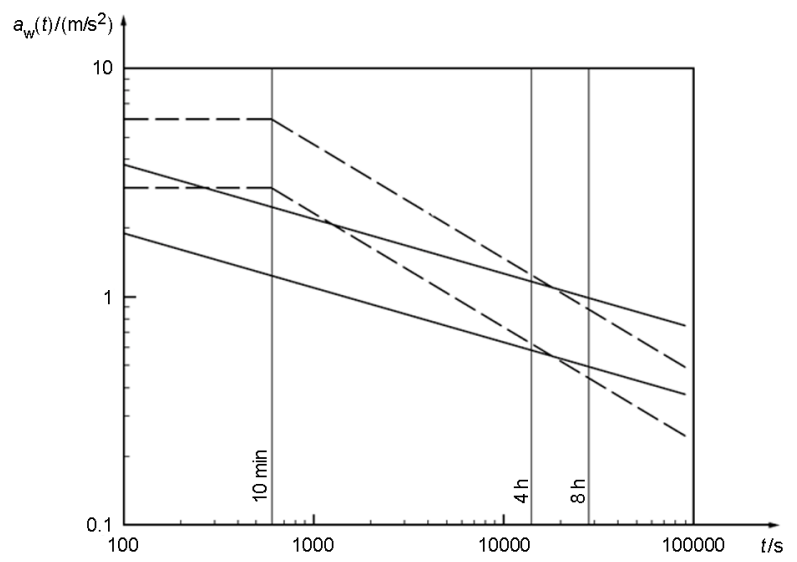

Figure 3. Health guidance caution zone

Table 2. Comfort level

\begin{tabular}{c|c}
\hline Acceleration $\left(\mathrm{m} / \mathrm{s}^{2}, \mathrm{RMS}\right)$ & Comfort level \\
\hline$<0.315$ & Not uncomfortable \\
\hline $0.315 \sim 0.63$ & A little uncomfortable \\
\hline $0.5 \sim 1.0$ & Fairly uncomfortable \\
\hline $0.8 \sim 1.6$ & Uncomfortable \\
\hline $1.25 \sim 2.5$ & Very uncomfortable \\
\hline$>2.0$ & Extremely uncomfortable \\
\hline
\end{tabular}

지각능력은 피크(peak) 가속도가 $0.015 \mathrm{~m} / \mathrm{s}^{2}$ 일 때 건강 한 사람의 $50 \%$ 가 진동을 감지 (detect) 할 수 있다고, 다소 애매하게 제시하고 있다.

멀미에 관해서는 $0.5 \mathrm{~Hz}$ 이하의 저주파 진동(예: 선박) 과 관련된 현상으로서, 특이한 점은 상하방향( $\mathrm{Z}$ 축)만 고려한다. 본 표준에서는 MSDV (Motion Sickness Dose Value)를 Z 축 가속도 제곱의 적분 제곱근으로 정의하고, 멀미를 호소하 는 사람의 백분율을 $\mathrm{K}_{\mathrm{m}} * \mathrm{MSDV}$ 의 식으로 나타낸다. $\mathrm{K}_{\mathrm{m}}$ 은 진동에 노출된 집단에 따라 변하는 상수로서, 남녀가 고르게 혼합된 집단에서는 $1 / 3$ 의 값을 사용한다. 일반적으로 여자가 남자보다 멀미를 심하게 하고, 나이가 많을수록 멀미증상의 빈도가 감소한다고 한다. 이 역시, 집단의 정의부터 모호한 점이 있다.

\section{Conclusion}

본 표준의 궁극적인 목표는 진동에 노출되는 작업자의 위 험을 최소화하는 것이다. 이를 위하여 노출한계와 조처한계 를 제시하고 있다. 그러나 이 한계치들의 정확성에 관해서는
논란이 있어 왔다. 만약 이 한계치들이 너무 낮게 설정된다 면 고용주와 장비제조업체의 부담이 증가할 것이고, 반면에 너무 높게 설정된다면 작업자의 건강이 위협받을 것이다. 따 라서 모든 표준에서 한계치를 설정하는 것은 매우 어렵고도 중요한 작업이다. 또한 진동에의 반응에는 개인적인 차이가 크므로 일률적인 한계치를 제시하는 것은 무리가 있다. 그럼 에도 불구하고 본 표준에서 한계치들을 제시하고 있는 것은 적용의 편리성을 위함과 함께, 작업자의 권리가 강하게 보장 받는 유럽국가들의 사회적인 분위기도 작용하고 있다고 사 료된다.

본 표준과 $\mathrm{ISO}$ 표준들과 비교해보면, 전술한 바와 같이 ISO 5349-1에서는 HAV와 진동성 백지증 증상과의 양반응 관계가 나타나 있다. $\mathrm{EU}$ 표준의 $\mathrm{HAV}$ 에 관한 조처한 계치 $\left(2.5 \mathrm{~m} / \mathrm{s}^{2}\right)$ 를 ISO 5349-1의 양-반응 관계(Figure 2) 에 대입해보면, 조처한계 수준의 HAV에 매일 8시간씩 약 12 년간 노출된다면 노출된 사람들의 약 $10 \%$ 가 진동성 백 지증의 증상을 나타낼 것이라고 예측된다. 만약 노출한계치 $\left(5 \mathrm{~m} / \mathrm{s}^{2}\right)$ 를 같은 방식으로 대입하면 잠복기는 약6년이 된다. 그리고 $\mathrm{EU}$ 표준의 $\mathrm{WBV}$ 에 관한 한계치들을 ISO 2631-1 의 주의영역(Figure 3)에 대입해보면 8시간 기준의 영역과 거의 같게 된다.

우리나라의 규제로는, 산업안전보건법에는 제 24 조(보건조 치)에 진동에 의한 건강장해를 예방하기 위하여 필요한 조 치를 하여야 하는 사업주의 의무를 명기하고 있다. 그리고 동법 시행령 제 32 조 8 항에 착암기 등에 의하여 신체에 강렬 한 진동을 주는 작업을 하는 경우, 유해 · 위험 예방조치 외 에 작업과 휴식의 적정한 배분, 그 밖에 근로시간과 관련된 근로조건의 개선을 통하여 근로자의 건강 보호를 위한 조치 를 하여야 한다고 규정되어 있다. 그리고 공장, 생활, 교통, 항공기와 관련한 소음 - 진동은 소음진동관리법에서 다루고 있다. 국내 규제에서 $\mathrm{EU}$ 표준처럼 한계치들을 제시하는 것 은 적절하지 않다고 사료되며, $\mathrm{EU}$ 표준에서 제시하고 있는 작업자의 안전 · 보건을 위한 고용주의 의무를 포함한 여러 포괄적인 사항들은 참조되어야 할 것이다.

한편, 본 표준의 역사가 길지 않고, ISO표준을 상대적으로 많이 사용하고 있으므로 본 표준을 적용한 결과들이 많이 보고되지는 않았다. 주로 유럽국가들을 중심으로 본 표준의 적용에 따른 연구 결과들이 종종 보고되고 있다. 그 중 가 장 최근의 것들만 살펴보면, 이탈리아에서는 908 종의 동력 수공구와 420 종의 운송수단의 진동을 측정하고 $\mathrm{EU}$ 표준과 의 비교를 수행하여 그 결과를 데이터베이스로 구축하였다 (Nataletti et al., 2008). Birlik(2009)는 철도 기관사들이 노출되는 전신진동을 측정한 결과, $\mathrm{EU}$ 표준의 한계치를 상회 하는 경우에는 ISO 2631-1의 주의영역에 해당됨을 보고하 였다. Coggins et al. (2010)은 건설업과 시설관리 작업자들 
이 사용하는 20 개 동력 수공구와 11 종류의 운송수단의 진 동수준을 측정하고, 본 $\mathrm{EU}$ 표준에서 제시하고 있는 한계치들 과 비교한 결과를 보고하였다. 우리나라에서는 시내버스의 진동을 $\mathrm{EU}$ 표준으로 평가한 결과가 보고된 바 있다(Cho et al., 2008). 추후 관련 연구들이 국내외에서 계속 수행될 것 이며, $\mathrm{EU}$ 표준의 여러 문제점에 대한 논의가 뒤따르기를 기 대한다. 현재로서는 $\mathrm{EU}$ 표준에서 제시하고 있는 노출한계와 조처한계의 정확성만을 기준으로 본 표준의 의의를 거론하 는 것은 적절하지 않다고 판단된다(Mansfield, 2004).

결론적으로, 본 표준은 기계류의 안전 설계를 규정한 'The Machinery Safety Directive 98/37/EC'와 함께 유럽인의 안전 · 보건을 위하여 적용되고 있다. 우리나라에서는 인체진 동에의 관심이 다른 선진국에 비하여 상대적으로 낮은 것을 감안하여 본 표준의 현장적용을 고려할 필요가 있겠다. 단, 한계치들의 적용을 위해서는 진동에의 반응에 있어 우리나 라 사람들과 서구인과의 차이점에 관한 연구가 선행되어야 함은 물론이다.

\section{Acknowledgements}

이 논문은 2010학년도 홍익대학교 학술연구진흥비에 의 하여 지원되었음.

\section{References}

Birlik, G., Occupational Exposure to Whole Body Vibration-Train Drivers, Industrial Health, 47(1), 5-10, 2009.

Cho, H. K., Park, I. S. and Park, H. L., The whole-body vibration evaluation of urban bus drivers, Proceeding of Winter Conference of the Korean Society of Occupational and Environmental Hygiene, 2008.

Coggins, M. A., van Lente, E., Mccallig, M, Paddan, G. and Moore, K.,
Evaluation of hand-arm and whole-body vibrations in construction and property management, Annals of Occupational Hygiene, 54(8), 904-914, 2010.

ISO, ISO 2631-1 Mechanical vibration and shock - Evaluation of human exposure to whole-body vibration - Part 1: General requirements, Geneva, 1997.

ISO, ISO 2631-1 Mechanical vibration and shock - Evaluation of human exposure to whole-body vibration - Part 1: General requirements, AMENDMENT 1, Geneva, 2010.

ISO, ISO 5349-1 Mechanical vibration - Measurement and evaluation of human exposure to hand-transmitted vibration - Part 1: General requirements, Geneva, 2001.

Mansfield, N. J., Human Response to Vibration, CRC Press, 2004.

Nataletti, P., Marchetti, E., Lunghi, A., Pinto, I., Stacchini, N. and Santini, F., Occupational exposure to mechanical vibration: the Italian vibration database for risk assessment, International Journal of Occupational Safety and Ergonomics, 14(4), 379-386, 2008.

The European Parliament and the Council of the European union, Directive 2002/44/EC on the minimum health and safety requirements regarding the exposure of workers to the risks arising from physical agents (vibration), Official Journal of the European Communities, 2002.

\section{Author listings}

Hee Sok Park: hspark@hongik.ac.kr

Highest degree: $\mathrm{Ph} . \mathrm{D}$. from The University of Michigan Position title: Professor, Department of Industrial Engineering, Hongik University, Seoul, Korea

Areas of interest: Industrial ergonomics, human vibration, usability engineering

Date Received : 2010-12-20

Date Revised : 2011-02-11

Date Accepted : 2011-02-11 